\title{
TRIPLE NEGATIVE APOCRINE CARCINOMA OF BREAST: A CASE REPORT
}

\author{
Devadhason Darwin Britto1, Arun Prasanth², Alankrith Ramesh Kashyap³, Floret Soundrapandian', Vidya Thiagu ${ }^{5}$
}

${ }^{1}$ Assistant Professor, Department of General Surgery, SRM Medical College Hospital and Research Centre, Chennai. 2 Postgraduate, Department of General Surgery, SRM Medical College Hospital and Research Centre, Chennai. 3 Postgraduate, Department of General Surgery, SRM Medical College Hospital and Research Centre, Chennai. 4 Professor, Department of General Surgery, SRM Medical College Hospital and Research Centre, Chennai. 5Postgraduate, Department of General Surgery, SRM Medical College Hospital and Research Centre, Chennai.

\section{ABSTRACT}

Apocrine carcinomas are very rare variant of invasive breast malignancies with an incidence less than $1 \%$ in the world. In this case report, we present a 40-year-old premenopausal female diagnosed with apocrine carcinoma and its distinct Androgen Receptor (AR) positivity and triple negativity for oestrogen, progesterone, and human epidermal growth factor receptor 2 neu.

\section{KEYWORDS}

Apocrine Carcinoma, Triple Negativity, Breast Malignancy.

HOW TO CITE THIS ARTICLE: Britto DD, Prasanth A, Kashyap AR, et al. Triple negative apocrine carcinoma of breast: a case report. J. Evolution Med. Dent. Sci. 2016;5(68):4937-4938, DOI: 10.14260/jemds/2016/1121

\section{INTRODUCTION}

Apocrine carcinomas also known as apocrine metaplasia or sweat gland carcinoma are very rare variant of invasive breast malignancies with an incidence less than 1\%. Apocrine changes in breast are seen during pregnancy and lactation period and in some benign lesions such as fibrocystic diseases of breast. Apocrine carcinomas are very difficult to differentiate from Infiltrating Ductal Carcinoma (IDC) and the prognosis is same as that of IDC.[1]

\section{CASE REPORT}

A 40-year-old female presented with painless lump in her left breast for 1 month. Fine needle aspiration cytology was done and revealed neoplastic lesions. Under general anaesthesia, Auchincloss modified radical mastectomy with axillary clearance was performed. Specimen of size $15 \times 12 \times 5 \mathrm{~cm}$ was sent to histopathological and Immunohistochemistry (IHC). Cut section of the specimen shows firm, solid growth of size $3 \times 2.5 \times 2 \mathrm{~cm}$ involving the upper and outer quadrants of mastectomy specimen (Fig. 1). 11 lymph nodes were present in the axillary pad of fat. Histological examination showed large polygonal tumour cells arranged in nests and sheets with abundant eosinophilic granular cytoplasm with pleomorphic vesicular nuclei and prominent nucleoli (Fig 2A). Tumour cells were found in clusters and showed distinct cell margins with apocrine snouting (Fig. 2B). All the lymph nodes were free of tumour. IHC studies showed that the tumour cells were negative for oestrogen, progesterone, and human epidermal growth factor receptor 2 neu and positive for androgen receptor profile.

Patient recovered well postoperatively and is on regular followup. She has already undergone first cycle of chemotherapy. Postoperative scar is healthy (Fig. 3).

Financial or Other, Competing Interest: None.

Submission 18-07-2016, Peer Review 10-08-2016,

Acceptance 17-08-2016, Published 25-08-2016.

Corresponding Author:

Dr. Alankrith R. K

Room 303, PG Medical Gents Hostel,

SRM College Hospital and Research Centre,

SRM Nagar, Kattankulathur,

Chennai-603203.

E-mail: koolchant@gmail.com

DOI: $10.14260 /$ jemds/2016/1121

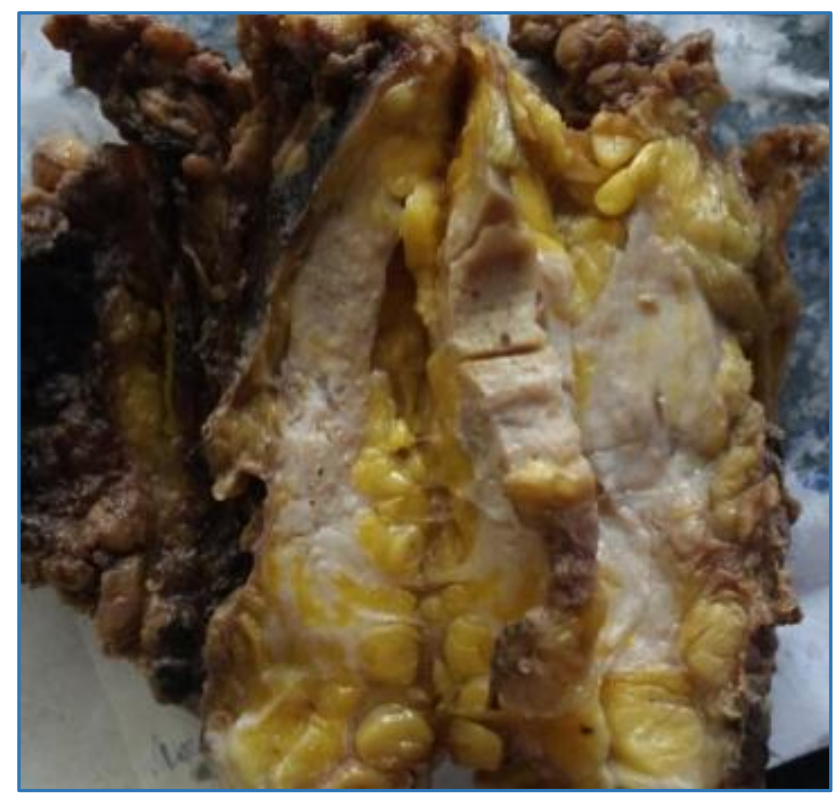

Fig. 1: Cut Section of Mastectomy Specimen showing: Greyish White Tumour (Red Arrow)
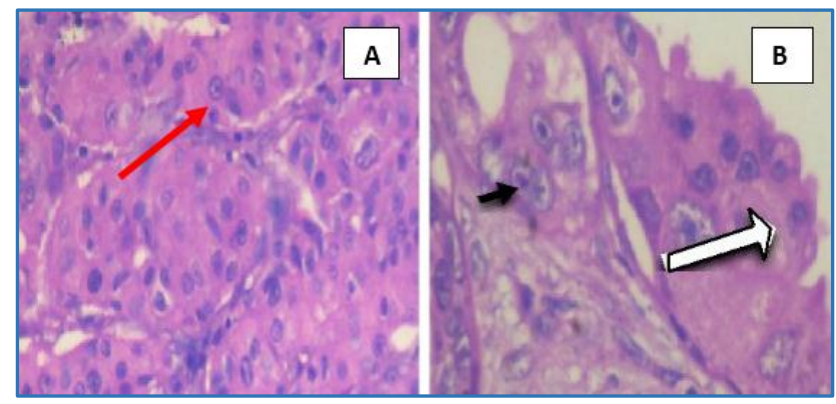

Fig. 2: A: Low-Power View showing Large Polygonal Tumour Cells Arranged in Nests. B: High-Power Field with Cells in Clusters and Apocrine Snouting (Large Hollow Arrow). Cells are showing Abundant Eosinophilic Granular Cytoplasm with Pleomorphic Vesicular Nuclei and Prominent Nucleoli (Small Black Arrow) 


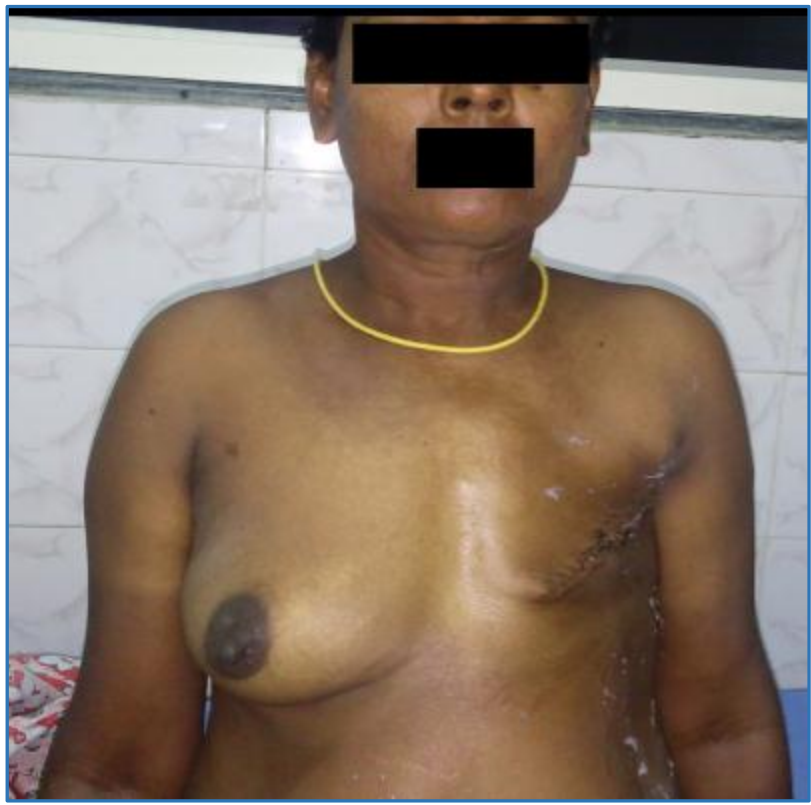

Fig. 3: Healthy Postoperative Scar

\section{DISCUSSION}

Apocrine carcinoma is a difficult to differentiate infiltrating ductal carcinoma and are more common in older and postmenopausal women with incidence less than $0.5 \%$ of all cancers.[1,2] Axilla, anogenital region, and eyelids are the most common areas where apocrine glands are seen. The main feature of apocrine carcinoma is overexpression of androgen receptor and low percentage of ER and PR positivity rate.[3,4] Japaze et al (2005) characterised apocrine carcinoma microscopically by their presence of abundant eosinophilic granular cytoplasm and a sharply defined cell border composing at least $75 \%$ of tumour cells prominent with multiple nucleoli.[5] Gilles et al (1994) described that clinical and radiological features of apocrine carcinomas of breast are similar to invasive ductal carcinoma. ${ }^{[6]}$ Likewise, the prognosis of grade and stage matched apocrine carcinoma with infiltrating ductal carcinoma shows no significant difference.[7,8] Since, there are no diagnostic or prognostic differences between apocrine and invasive ductal carcinomas identifying the AR positivity status will lead to different management protocol. Therefore, apocrine carcinomas should be identified as separate entity.

\section{CONCLUSION}

Apocrine carcinoma of the breast is a rare and distinct morphological-type carcinoma. It should be diagnosed as a separate entity because of the different hormonal profile and may present with distinct clinical behaviour with a unique response to targeted therapy with androgen receptor antagonist.

\section{REFERENCES}

1. Matsuo K, Fukutomi T, Hasegawa T, et al. Histological and immunohistochemical analysis of apocrine breast carcinoma. Breast Cancer 2002;9(1):43-9.

2. Celis JE, Gromova I, Gromov P, et al. Molecular pathology of breast apocrine carcinomas: a protein expression signature specific for benign apocrine metaplasia. FEBS Lett 2006;580(12):2935-44.

3. Gatalica Z. Immunohistochemical analysis of apocrine breast lesions: consistent overexpression of androgen receptor accompanied by the loss of oestrogen and progesterone receptors in apocrine metaplasia and apocrine carcinoma in situ. Pathol Res Pract 1997;193(1112):753-8.

4. Tsutsumi Y. Apocrine carcinoma as triple-negative breast cancer: novel definition of apocrine-type carcinoma as oestrogen/progesterone receptor negative and androgen receptor positive, invasive ductal carcinoma. Jpn J Clin Oncol 2012;42(5):375-86.

5. Japaze H, Emina J, Schwam RJ, et al. Pure invasive apocrine carcinoma of the breast: a new clinicopathological entity? Breast 2005;14(1):3-10.

6. Gilles R, Lesnik A, Guinebretiere JM, et al. Apocrine carcinoma: clinical and mammographic features. Radiology 1994;190(2):495-7.

7. d'Amore ES, Terrier-Lacombe MJ, Travagli JP, et al. Invasive apocrine carcinoma of the breast: a long-term followup study of 34 cases. Breast Cancer Res Treat 1988;12(1):37-44.

8. Abati AD, Kimmel M, Rosen PP. Apocrine mammary carcinoma: a clinicopathologic study of 72 cases. Am J Clin Pathol 1990;94(4):371-7. 